alloy- and metal-glass seals now available, and prophesied the general use of low vapour pressure hydrocarbon oils, as prepared by Birch, in diffusion pumps. The demonstrations were of great beauty and special mention may be made of three-the method of preparing electrostatic screens in vacuo by distillation of metallic silver, the renewal of alkali metal traps by passing sodium ions electrolytically through soda glass, and finally the use of magnesium as a 'getter', the distillation being effected by means of electron bombardment.

The concluding address, the subject of which had been puzzling members for some time, was given by Dr. MacGregor Skene on "Charles and Erasmus". $\mathrm{He}$ was referring to Erasmus Darwin and his famous grandchild, who still remains, said Dr. MacGregor Skene, the greatest and best protagonist of his evolutionary theory.

The trade exhibition of apparatus and books was held in the Physies Department. There were many examples of good workmanship, especially the epidiascopes, which were displayed to full advantage in the optical laboratories. The bakelite cases for balance weights were interesting. Of outstanding interest was the display of the cycle film by Messrs. Dance-Kaufmann. This formed the subject of a demonstration and discussion initiated by Mr. H. E. Dance. The value of such films was at once apparent in the illustration of the theory of wave motion, and of the three-phase induction motor. An advantage is that only one effect is illustrated at a time, hence the teacher never loses control due to excessive detail, as is often the case in documental films. The projectors, equally adaptable to continuous and stationary films, may be operated by hand, or, in the more expensive model, by an electric motor, and can be used in daylight. The conditions of the demonstration were, throughout, those likely to be found in the class-room. The manufacturers are desirous of producing additional films of an educational type and wish to have the co-operation of science masters in editing these.

The conference, which by general agreement had been one of the most successful of recent years, ended fittingly with a tour to Cheddar in most glorious weather.

\title{
Lectures at the Physical Society's Exhibition*
}

\section{Measurement of Surface Tensions}

$\mathrm{T}$ HE first of the evening discourses associated with the Physical Society's twenty-third annual exhibition at the Imperial College of Science and Technology was delivered on January 3 by Dr. Allan Ferguson on "Surface Tension and its Measurement". Simple illustrative experiments were appealed to in order to demonstrate the existence of a surface tension in liquid films and surfaces, and the variation of this tension with temperature and with the nature of the liquid. Conditions of instability were illustrated experimentally, and it was pointed out that a knowledge of the quantitative laws governing these phenomena, together with an appeal to the principle of minimum potential energy, would go far to elucidate otherwise obscure phenomena.

Of the quantitative laws, the power law connecting surface tension and temperature, and Macleod's law connecting surface tension and density, together with the law of rectilinear diameters, give formulæ which represent very closely the temperature variation of liquid and vapour density, and of free and total molecular surface energy.

Conditions of drop formation were demonstrated and the formation of aniline drops in water was shown by projection, and also by means of a slow motion cinematograph film. The impact on a solid surface of an aniline drop in water was also demonstrated cinematographically, as were some of Worthington's results for the impact of liquid drops on liquid and solid surfaces.

A brief discussion was given of the principal methods for the measurement of surface tension. Simple conditions for the production and photographic measurement of large flat bubbles were reviewed, and it was pointed out that the method can be successfully used for the measurement of interfacial tensions.

Quantitative determinations of the surface tension of benzene were made by the capillary rise method, by means of the pull on a plate, and finally, by a

* The lectures are being published in the February issue of the Journal of Scientific Instruments. method which involves the use of no more than a few cubic millimetres of liquid, a knowledge of its density being unnecessary. The methods were in each instance so arranged as to be direct-reading on scales visible to the audience.

\section{Cathode Ray Osolllography}

Mr. R. A. Watson Watt's lecture on January 4 at the Physical Society's Exhibition touched on a variety of aspects of cathode ray oscillography. He referred to 'domesticated oscillograms', the electrically-recorded gramophone record and the sound-track on the 'talkie' film, as illustrating the problems and limitations of oscillography, and then proceeded to discuss the special merits of the cathode ray oscillograph. It provides a radical solution of the opposing requirements of low inertia and high photographic effect which face the designer of mechanical oscillographs, it has an exceptionally high overload capacity, and the highvoltage type is ultimately limited in speed of operation only by the errors due to the finite time of transit of the indicating electrons through the deflecting field produced by the E.M.F's under examination.

Mr. Watson Watt showed slides of oscillograms, one delineating wave trains of frequency 25 million per second, corresponding to a wireless wave-length of 12 metres, and another of still higher frequency phenomena in which a trace described in $10^{-9}$ sec. the time taken for light to travel $30 \mathrm{~cm}$.- -was clearly recorded. In this latter case the electron velocity in the recording jet was about half that of light, the transverse writing speed about one-fifth that of light.

Turning to the low-speed sealed-off oscillograph, Mr. Watson Watt enumerated the residual defects, mainly due to the gas content utilised as an aid to focusing, which still mar slightly the remarkably fine performance of modern tubes of this simple character.

The lecture was illustrated by demonstrations using eight oscillographs in all, a battery of five in parallel arranged around the lecture theatre, and three independent tubes of special construction. A demonstration of particular interest was the optical projection, throughout all the experiments, of the 
moving screen image from the central tube of the paralleled group on to a screen approximately two feet square, with a tenfold magnification. This projected image was clearly visible from the back of the theatre although an accelerating voltage less than 2,000 was used on the tube. There was a striking contrast between the red fluorescence of the 'port' member of the group and the brilliant green of the 'starboard' tube.

In addition to experiments showing the applications of the oscillograph in radio research, Mr. Watson Watt exhibited a cinematograph film from the same field. The most novel section of the film might, he suggested, be called "Sturm über Europa", as it represented a single minute of the thunderstorm history of Europe. The places of origin of individual atmospherics-located by simultaneous cathode ray cinematography on a base-line Slough-Leucharswere indicated by bright flashes on a dark map of Europe, the timing of the flashes reproducing accurately the times of incidence of the individual atmos. pherics. The film showed that, within a single halfminute of recording, lightning flashes in mid-Atlantic, the North Sea, Denmark, Germany, Hungary, the Balkans, and France had contributed to the stream of atmospheries affecting Great Britain.

The lecture concluded with demonstrations of the variety of colour and duration of afterglow in screen materials, of the control of brightness by a Wehnelt cylinder, and of the applications of oscillographs fitted with Faraday cages to operations in which oscillographic response and relay control are combined.

The oscillographs used in the demonstrations were lent by the manufacturers, Messrs. A. C. Cossor, Ltd.

\section{Time Measurement: Old and New}

The last of the evening discourses at the Physical Society's exhibition was given by Mr. Hope-Jones on January 5 on "Time Measurement: Old and New". With the kind permission of Sir Henry Lyons, the director of the Science Museum, he was enabled to begin his lecture by exhibiting the Dover Castle clock, still going, although a relic of the fourteenth century. He showed lantern slides of the half-dozen known examples of this period, de Vick, Wells̃, Cassiobury, Salisbury, Porlock and Dinan, and expressed the hope that others will be found to have escaped the scrap-heap or restoration by a vandal clockmaker.

Mr. Hope-Jones traced the origin of the astronomical dial (a few of which survived the dissolution of the monasteries, such as Glastonbury, Wells, Wimborne and Hampton Court) from the Ptolemaic or geocentric conception of the universe, and showed models of Galileo's and Huyghens' escapements which harnessed the pendulum to wheelwork, thus bringing to a close the medieval period of 300 years during which the only known regulator for clocks and watches was the Foliot balance.

The halcyon days of English clock-making, inaugurated by Robert Hook, Harrison, Arnold and Earnshaw were discussed, and Mr. Hope-Jones deplored the fact that when Tompion and Graham were laid to rest in Westminster Abbey, the science of accurate time measurement died with them, or rather remained for two hundred years exactly in the condition in which they left it. $\mathrm{He}$ attributed this to the escapement, which had 'mesmerised' horology for so long, and showed how the "Synchronome" remontoire produces perfect freedom of the pendulum by coupling two together as 'master' and 'slave', a feat accomplished by Mr. Shortt's invention of the hit-and-miss synchroniser.

The extraordinary effects of the new standard of time-keeping set up by this clock were rapidly reviewed: how it caused the astronomers to invert their methods of producing rate charts; how it revealed nutation and necessitated a revision of the definition of time in the Nautical Almanac, and finally how the lunar period appeared in comparison with the crystal clock, although the change in the value of $G$ only affects the rate by $2 / 10,000$ sec. at maximum between lunar noon and midnight.

Prof. C. V. Boys has dubbed Mr. Hope-Jones as a modern Saint Athanasius, saying "this is the clock faith which, unless a man believe faithfully, he cannot be saved", subscribing to its articles himself, "with the possible reservation of some of its damnatory clauses". Whilst discouraging the use of the new synchronous motor clock for the time equipment of large buildings and institutions, $\mathrm{Mr}$. Hope-Jones proclaimed the engineers of the electric light and power stations as the future time-keepers of the nation, and described means of assisting them to keep their turbo-alternators running true to average Greenwich Mean Time.

\section{Annual Meeting of the Mathematical Association}

$\mathrm{T}$ HE annual meeting of the Mathematical Association was held in London at the Institute of Education on January 5 and 6 . The most notable features of the meeting were the presidential address by Prof. G. N. Watson and a discussion on "The Study of Statistics in a School Course". Prof. Watson's address had the mysterious title of "The Marquis and the Land Agent; a Tale of the Eighteenth Century". It was revealed as a topic from the history of mathematics. The speaker regretted that as a pure mathematician he could not speak on some popular subject from the 'real' world of the applied mathematician. Neither could a popular discourse be made on those researches into singular moduli which had engaged his leisure during the past two years. Pedagogical problems he regarded as of secondary importance. Only a historical subject remained.
The Marquis of the title was the Italian mathematician Guilio Carlo, Count Fagnano and Marquis de Toschi (1682-1766). English textbooks refer to him as Fagnano and mention a theorem concerning elliptic arcs. The 'land agent' was the English amateur, John Landen (1719-90) who was in the service of Earl Fitzwilliam from 1762 until 1788. His name is familiar in 'Landen's transformation' for an elliptic integral.

The tale uniting these two was their work on rectifying elliptic arcs and manipulating the corresponding integrals. In 1691, Bernoulli had discovered that it is possible to find arcs of a parabolic spiral which are of equal length but are not congruent. Fagnano obtained similar results for the lemniscate, and enunciated the general theorem that if $m$ is an integer, a quadrant of the lemniscate can be divided into $2^{m}$ or $3 \times 2^{m}$ or $5 \times 2^{m}$ equal parts. Amongst his results occur rudimentary forms of the addition ๑) 1933 Nature Publishing Group 